\title{
Parkin-mediated ubiquitination of mutant glucocerebrosidase leads to competition with its substrates PARIS and ARTS
}

\author{
Inna Bendikov-Bar ${ }^{1}$, Debora Rapaport ${ }^{1}$, Sarit Larisch ${ }^{2}$ and Mia Horowitz ${ }^{*}$
}

\begin{abstract}
Background: Parkinson's disease (PD) is a movement neurodegenerative disorder characterized by death of dopaminergic neurons in the substantia nigra pars compacta of the brain that leads to movement impairments including bradykinesia, resting tremor, postural instability and rigidity. Mutations in several genes have been associated with familial PD, such as parkin, pink, DJ-1, LRKK2 and a-synuclein. Lately, mutations in the GBA gene were recognized as a major cause for the development of PD.

Mutations in the GBA gene, which encodes for lysosomal $\beta$-glucocerebrosidase (GCase), lead to Gaucher disease (GD), an autosomal recessive sphingolipidosis characterized by accumulation of glucosylceramide, mainly in monocyte-derived cells. It is a heterogeneous disease, with Type 1 patients that do not present any primary neurological signs, and Type 2 or Type 3 patients who suffer from a neurological disease. The propensity of type 1 GD patients and carriers of GD mutations to develop PD is significantly higher than that of the non-GD population. We have shown in the past that parkin and mutant GCase, expressed in heterologous systems, interact with each other, and that normal but not mutant parkin mediates K48-dependent proteasomal degradation of mutant GCase variants.
\end{abstract}

Methods: We tested possible competition between mutant GCase and PARIS or ARTS on the E3 ubiquitin ligase parkin, using coimmunoprecipitation assays and quantitative real-time PCR.

Results: We show that endogenous mutant GCase variants associate with parkin and undergo parkin-dependent degradation. Mutant GCase competes with the known parkin substrates PARIS and ARTS, whose accumulation leads to apoptosis. Dopaminergic cells expressing mutant GCase are more susceptible to apoptotic stimuli than dopaminergic cells expressing normal GCase, present increased cleavage of caspase 3 and caspase 9 levels and undergo cell death.

Conclusions: Our results imply that presence of mutant GCase leads to accumulation of parkin substrates like PARIS and ARTS, which may cause apoptotic death of cells.

Keywords: Gaucher disease, Parkinson disease, Glucocerebrosidase, Paris, Arts

\footnotetext{
* Correspondence: horwitzm@post.tau.ac.il

${ }^{1}$ Department of Cell Research and Immunology, Life Sciences, Tel Aviv

University, Levanon St, Ramat Aviv 69978, Israel

Full list of author information is available at the end of the article
}

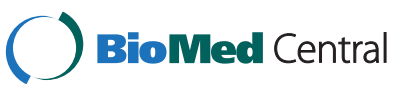

(c) 2014 Bendikov-Bar et al.; licensee BioMed Central Ltd. This is an Open Access article distributed under the terms of the Creative Commons Attribution License (http://creativecommons.org/licenses/by/4.0), which permits unrestricted use, distribution, and reproduction in any medium, provided the original work is properly credited. The Creative Commons Public Domain Dedication waiver (http://creativecommons.org/publicdomain/zero/1.0/) applies to the data made available in this article, unless otherwise stated. 


\section{Background}

Gaucher disease (GD) is an autosomal recessive disease characterized by accumulation of glucosylceramides, mainly in monocyte derived cells. Due to its heterogeneity, it has been divided to Type 1 GD, primarily a nonneurological disease, and Type 2 and 3, two forms associated with a neuronopathic disease [1,2]. Mutant glucocerebrosidase (GCase) variants undergo ER-associated degradation (ERAD), the degree of which correlates with disease severity [3]. ER-retained mutant GCase leads to ER stress and to unfolded protein response [4].

There is a significantly higher propensity of GD patients or carriers of GD mutations to develop Parkinson's disease (PD) compared to the general population [5-19], indicating that not only GD pathology but even the presence of one mutant GBA allele increases the risk for the development of PD.

PD, the second most common neurodegenerative disorder, is characterized by a progressive loss of dopaminergic neurons in the substantia nigra pars compacta of the midbrain $[20,21]$. It is also associated with the appearance of Lewy bodies (composed of $\alpha$-synuclein and ubiquitin), depletion of striatal dopamine and gliosis. PD pathology also manifests in non-dopaminergic nerve cells such as olfactory and brain stem neurons, and actually precedes the pathological changes seen in dopaminergic neurons [22]. Motor symptoms in patients, including slowness of movement, resting tremor, rigidity, postural instability and gait difficulty, usually appear after a massive loss of dopamine from the striatum [23]. PD patients may also present nonmotor manifestations such as dementia and psychiatric symptoms [24].

GD is associated with glucosylceramide accumulation and pathogenic presence of mutant GCase, yet it is still unclear whether both contribute to development of PD in GD patients and carriers of GD mutations. One theory suggests a role for glucosylceramide accumulation in $\alpha$-synuclein aggregation [25]. However, there are no documented reports on accumulation of glucosylceramide in brains of Type 1 GD patients, nor in brains of carriers of GD mutations, raising the possibility that the development of PD in GD patients or in carriers of GD mutations is due to the presence of mutant GCase.

We have shown in the past that mutant GCase undergoes parkin-mediated K48 polyubiquitination and proteasomal degradation. Parkin, a multifunctional RING (Really InterestiNG) domain-containing E3 ubiquitin ligase encoded by the PARK2 gene is a cytoplasmic protein, mutations in which are the most common cause $(\sim 50 \%)$ of autosomal recessive PD [26,27]. Parkin regulates diverse functions in the cell, including receptor-mediated trafficking, cell signaling, autophagy and mitochondrial quality control [28]. Parkin regulates receptor-mediated trafficking and signaling through monoubiquitination of substrates [29]. It regulates inclusion body formation and autophagy through lysine 29 and 63 polyubiquitination [30,31]. Parkin also mediates lysine 48 polyubiquitination of substrates, which are destined to proteasomal degradation [28,32]. Loss-of-function mutations in the PARK2 gene lead to accumulation of non-cleared lysine48 substrates. Accumulation of the known parkin substrates PARIS [33] and ARTS [34] is pathogenic to cells. Such accumulation was found in post mortem brains of PD patients and in a mouse model of PD mutated in PARK2 [35], indicating that the loss of parkin function contributes to PD pathogenesis.

In this study we used GD-derived skin fibroblasts to show that endogenous mutant GCase associates with parkin and undergoes parkin-dependent degradation. We utilized human dopaminergic cells in tissue culture to demonstrate competition between mutant GCase and the known parkin substrates PARIS and ARTS, whose accumulation leads to apoptosis of cells.

\section{Material and methods \\ Materials}

The following antibodies were used in this study: monoclonal anti-GCase 2E2 (Abnova), generated against a peptide corresponding to amino acids 146-236 of human GCase, rabbit polyclonal anti-GCase, generated against a peptide corresponding to amino acids 517-536 of human GCase (G4171, Sigma), rabbit anti-ERK (C16 Santa Cruz Biotechnology, Santa Cruz, CA, USA), mouse monoclonal anti-actin (MP Biomedicals, OH, USA), mouse monoclonal anti-myc and anti-GFP (Cell Signaling Technology, Beverly, MA, USA); Secondary antibodies: horseradish peroxidaseconjugated goat anti-mouse or goat anti-rabbit (Jackson Immuno Research Laboratories, West Grove, PA, USA), rabbit anti-caspase 3 and rabbit anti-cleaved caspase 9 (Cell Signaling Technology, Beverly, MA, USA).

Carbobenzoxy-L-leucyl-L-leucyl-L-leucinal (MG132), cyclohexamide (CHX), Leupeptin and phenylmethylsulfonyl fluoride (PMSF) were purchased from Sigma-Aldrich (Rehovot, Israel). Four-methyl-umbelliferyl-glucopyranoside (4-MUG) was purchased from Genzyme Corp (Cambridge, MA, USA). Nonidet P-40 (NP-40) was purchased from Roche Diagnostics (Mannheim, Germany). Absolute Blue qPCR SYBR Green ROX Mix was from TAMAR Laboratory Supplies (Mevaseret Zion, Israel).

\section{Cell lines}

Human primary skin fibroblasts cell lines are described in Table 1. Fibroblasts and SHSY5Y human dopaminergic cells were grown in Dulbecco's modified Eagle's medium (DMEM) supplemented with $20 \%$ fetal calf serum (FCS), $100 \mathrm{U} / \mathrm{ml}$ penicillin-streptomycin, $1 \mathrm{mM}$ sodium pyruvate and $2 \mathrm{mM}$ L-glutamine (Biological Industries, Beit-Haemek, 
Table 1 Description of cell lines used in the study

\begin{tabular}{ccccc}
\hline Patient \# & Genotype & Disease type & Age (years) & Sex \\
\hline 1 & Normal & Normal & 57 & $\mathrm{~F}$ \\
2 & Normal & Normal & UN* & UN* \\
3 & L444P/L444P & 3 & 1 & $\mathrm{~F}$ \\
4 & L444P/L444P & 3 & 1 & $\mathrm{~F}$ \\
5 & L444P/L444P & 3 & 2 & $\mathrm{~F}$ \\
6 & L444P/L444P & 3 & 3 & $\mathrm{~F}$ \\
7 & L444P/ReCNci & 2 & 1 & $\mathrm{M}$ \\
8 & N370S/N370S & 1 & 43 & $\mathrm{~F}$ \\
9 & R131C/R131C & 2 & 1 month & $\mathrm{F}$ \\
10 & L444P/R120W & 2 & 1 & $\mathrm{~F}$ \\
11 & L444P/P415R & 2 & 11 months & $\mathrm{F}$ \\
12 & N370S/N370S & 1 (severe) & 11 & $\mathrm{M}$ \\
13 & N370S/N394L & 1 & 30 & $\mathrm{M}$ \\
14 & K157Q/D140H_E326K & 1 & 26 & $\mathrm{M}$ \\
15 & K157Q/D140H_E326K & 1(severe) & 13 & $\mathrm{M}$ \\
\hline
\end{tabular}

The table contains information on genotype, GD type, sex and age at diagnosis of the GD-derived fibroblast lines and normal fibroblasts. *UN-Unknown (biopsy was taken anonymously due to Israeli Helsinki requirements, with no tracking back information).

Israel), at $37^{\circ} \mathrm{C}$ in the presence of $5 \% \mathrm{CO}_{2}$. SHSY5Y stably expressing different human GCase variants were described elsewhere [36].

\section{Construction of plasmids}

Construction of myc-His-GCase plasmids was described elsewhere [36]. pSC2-6myc ARTS was described in [34]. MISSION shRNA plasmid (TRCN0000000285) encoding parkin-targeted shRNA was purchased from Sigma-Aldrich (St Louis, Mo, USA).

To construct the PARIS-expressing vector, a $1.9 \mathrm{~kb}$ PARIS cDNA fragment was amplified using Phusion high-fidelity DNA polymerase (New England Biolabs, Ipswich, USA) from the plasmid cFUGW-lenti-PARIS, a kind gift from Dr. Ted M. Dawson (Solomon H. Snyder Department of Neuroscience, Johns Hopkins University School of Medicine, Baltimore, Maryland, USA). The PARIS cDNA fragment was cloned into the Ecl136II site of pEGFPC3 vector plasmid (Clontech Laboratories Inc. CA, USA). Gibson assembly technology (New England Biolabs, Ipswich, USA) was used for the cloning. For knockdown of parkin, MISSION short hairpin RNA (shRNA) plasmids, encoding small interfering RNAs (siRNAs) targeting parkin, were purchased from Sigma Aldrich (St Louis, Mo, USA). Of all the existing vectors, TRCN0000000285 successfully knocked down human parkin. As a control, a pLKO.1 plasmid (Sigma Aldrich, St Louis, Mo, USA) harboring shRNA against GFP was used.

\section{RNA preparation}

Total RNA was isolated using the EZ-RNA kit (Biological Industries, Beit Haemek, Israel), according to the manufacturer's instructions.

\section{RT PCR}

Two micrograms of RNA were reverse transcribed with M-MLV reverse transcriptase (Promega corporation, CA, USA), in the presence of $1 \mu \mathrm{g}$ oligo-dT primer in a total volume of $20 \mu \mathrm{l}$, at $42^{\circ} \mathrm{C}$ for 60 minutes. Reactions were stopped by incubation at $70^{\circ} \mathrm{C}$ for 15 minutes. One-two microliters of the resulting cDNA were amplified by quantitative real-time PCR.

\section{Quantitative real-time PCR}

One microliter of CDNA was used for real-time PCR. PCR was performed using the KAPA SYBR Fast Universal qPCR kit (Kapa Biosystems, Wilmington, MA, USA) in a Rotor-Gene 6000 (Corbett life sciences, Valencia, CA, USA). The reaction mixture contained 50\% qPCR mix, $300 \mathrm{nM}$ of forward primer (5'-ATCTGAAGGAGC AACATCTGG-3') and $300 \mathrm{nM}$ of reverse primer (5'CACGGGCGAGTTTACTATGTAG-3'), in a final volume of $10 \mu \mathrm{l}$. Thermal cycling conditions were: $95^{\circ} \mathrm{C}(10 \mathrm{mi}-$ nutes), 40 cycles of $95^{\circ} \mathrm{C}$ (10 seconds), $60^{\circ} \mathrm{C}$ (20 seconds) and $72^{\circ} \mathrm{C}$ (20 seconds). Relative gene expression was determined by $\mathrm{Ct}$ value.

\section{SDS-PAGE and western blotting}

Cell monolayers were washed three times with ice-cold phosphate-buffered saline (PBS) and lysed at $4^{\circ} \mathrm{C}$ in $500 \mu \mathrm{l}$ of lysis buffer (10 mM HEPES pH 8.0, $100 \mathrm{mM}$ $\mathrm{NaCl}, 1 \mathrm{mM} \mathrm{MgCl}_{2}$ and $1 \%$ Triton X-100) containing $10 \mu \mathrm{g} / \mathrm{ml}$ aprotinin, $0.1 \mathrm{mM}$ PMSF and $10 \mu \mathrm{g} / \mathrm{ml}$ leupeptin. Lysates were incubated on ice for 30 minutes and centrifuged at $10,000 \mathrm{~g}$ for 15 minutes at $4^{\circ} \mathrm{C}$. Samples, containing the same amount of protein, were electrophoresed through 10\% SDS-PAGE and electroblotted onto a nitrocellulose membrane (Schleicher and Schuell BioScience, Keene, NH, USA). Membranes were blocked with $5 \%$ skim milk and $0.1 \%$ Tween-20 in Tris-buffered saline (TBS) for 1 hour at room temperature (RT) and incubated overnight with the primary antibody. The membranes were then washed three times in $0.1 \%$ Tween20 in TBS and incubated with the appropriate secondary antibody for 1 hour at RT. After washing, membranes were reacted with ECL detection reagents (Santa Cruz Biotechnology Inc., CA, USA) and analyzed by luminescent image analyzer (X-OMAT 2000 Processor, Kodak, Rochester, NY, USA).

\section{Transfections}

SHSY5Y cells were transfected using either a MP-100 Microporator (Digital Bio Tech, Seoul, South Korea) 
according to the manufacturer's instructions, or Lipofectamine $2000^{\text {Ts }}$ (Invitrogen, CA, USA).

\section{Immunoprecipitation}

Subconfluent skin fibroblasts were treated overnight with $25 \mu \mathrm{M}$ MG-132, after which cells were washed 3 times with ice-cold PBS and lysed at $4^{\circ} \mathrm{C}$ in $1 \mathrm{ml}$ of lysis buffer $(10 \mathrm{mM}$ Hepes $\mathrm{pH}=8,100 \mathrm{mM} \mathrm{NaCl}, 1 \mathrm{mM}$ $\mathrm{MgCl}_{2}$, and $0.5 \% \mathrm{NP}-40$ ) containing $10 \mu \mathrm{g} / \mathrm{ml}$ aprotinin, $0.1 \mathrm{mM}$ PMSF and $10 \mu \mathrm{g} / \mathrm{ml}$ leupeptin (Sigma-Aldrich, Rehovot, Israel). Following centrifugation at $10,000 \mathrm{~g}$ for 15 minutes at $4^{\circ} \mathrm{C}$, the supernatants were pre-cleared for 2 hours at $4^{\circ} \mathrm{C}$ with protein A-agarose (Roche Diagnostic, Mannheim, Germany). Following washes with $1 \mathrm{ml}$ of lysis buffer containing protease inhibitors, proteins were eluted for 10 minutes at $100^{\circ} \mathrm{C}$ with $5 \mathrm{X}$ loading buffer, electrophoresed through 10\% SDS-PAGE and blotted. The corresponding blot was interacted with the appropriate antibodies.

\section{Ubiquitination in tissue culture}

Sub-confluent skin fibroblasts were treated overnight with $25 \mu \mathrm{M}$ MG-132, after which stringent immunoprecipitation conditions were applied as previously described [37], with some modifications. The medium was aspirated and the cells were harvested and lysed in $100 \mu \mathrm{l}$ of denaturing buffer (1\% SDS, $50 \mathrm{mM}$ Tris pH7.4, $140 \mathrm{mM} \mathrm{NaCl}$ ). Following vigorous vortexing, the lysates were immediately boiled for 10 minutes, cleared by centrifugation at $10,000 \mathrm{~g}$ for 10 minutes and diluted 10 fold into buffer containing $2 \%$ Triton X-100, $50 \mathrm{mM}$ Tris $\mathrm{pH} 7.4,140 \mathrm{mM} \mathrm{NaCl}$. After additional centrifugation to remove any insoluble material, immunoprecipitation was carried out with monoclonal anti-GCase antibody. Following three washes (5\% sucrose, Tris pH7.5, $50 \mathrm{mM}$ $\mathrm{NaCl}, 0.5 \% \mathrm{NP} 40$, EDTA $5 \mathrm{mM}$ ) the ubiquitin-GCase conjugates were resolved through SDS-PAGE and the corresponding blots were interacted with polyclonal anti-GCase antibodies.

\section{Proteasome inhibition}

Cells were treated for 24 hours with $25 \mu \mathrm{M}$ MG132, after which they were processed according to the experiment performed (western blotting with or without immunoprecipitation).

\section{Quantification}

The blots were scanned using Image Scan and the intensity of each band was measured by the Image Master 1DPrime densitometer (both from Amersham Pharmacia Biotech, Buckinghamshire, England). To quantify the results, the intensity of the tested protein at each lane was divided by the intensity of the loading control (actin or
ERK) in the same lane. The value obtained for nontransfected cells or WT cells was considered as 1 .

\section{Results}

Endogenous mutant GCase undergoes polyubiquitination and interacts with parkin

We have already shown that the L444P mutant GCase variant undergoes ubiquitination [38]. In order to confirm ubiquitination of other mutant variants, GCase-containing complexes were immunoprecipitated from lysates that originated from fibroblasts of GD patients, separated through SDS-PAGE and the corresponding blot was interacted with anti-GCase antibodies. As presented in Figure $1 \mathrm{~A}$ and $\mathrm{B}$, there was a visible ubiquitination of severe mutant GCase variants, while ubiquitination of the N370S mutation was non visible, as expected for a mild mutation $[2,39]$. It is worth mentioning that the N370S homozygous cells were derived from a mild patient (patient no. 8, Table 1).

\section{Parkin interacts with mutant GCase in GD fibroblasts}

We have shown in the past that parkin and mutant GCase, expressed in heterologous systems, interact with each other. Moreover, parkin mediates polyubiquitination and proteasomal degradation of mutant, but not normal transfected GCase [36]. In the present study, we aimed at confirming the interaction between endogenous parkin and mutant GCase. In order to do so, we first set out to demonstrate the expression of parkin in skin fibroblasts (Figure 1C). At the next stage, parkin-containing complexes were immunoprecipitated from lysates prepared from GD skin fibroblasts and from normal skin fibroblasts, after which the corresponding blot was interacted with anti-GCase antibody. The results presented in Figure 1D and E show that mutant GCase, but not its normal counterpart, interacted with parkin.

\section{Parkin mediates degradation of endogenous mutant GCase}

To confirm that parkin not only interacts with endogenous GCase but also mediates its degradation, the effect of overexpression of normal or mutant parkin (T240R ligase dead parkin) was tested in skin fibroblasts that originated from GD patient, homozygous for the L444P mutation, or in normal skin fibroblasts. The results, presented in Figure 2A and B, indicated that overexpression of normal, but not mutant, parkin in cells that originated from GD patient led to a significant decrease in GCase level. However, the level of GCase in normal skin fibroblasts was not affected by parkin overexpression. These results strongly suggest that parkin mediates degradation of mutant but not normal GCase.

To further confirm that parkin mediates degradation of mutant GCase, normal skin fibroblasts or GD-derived 

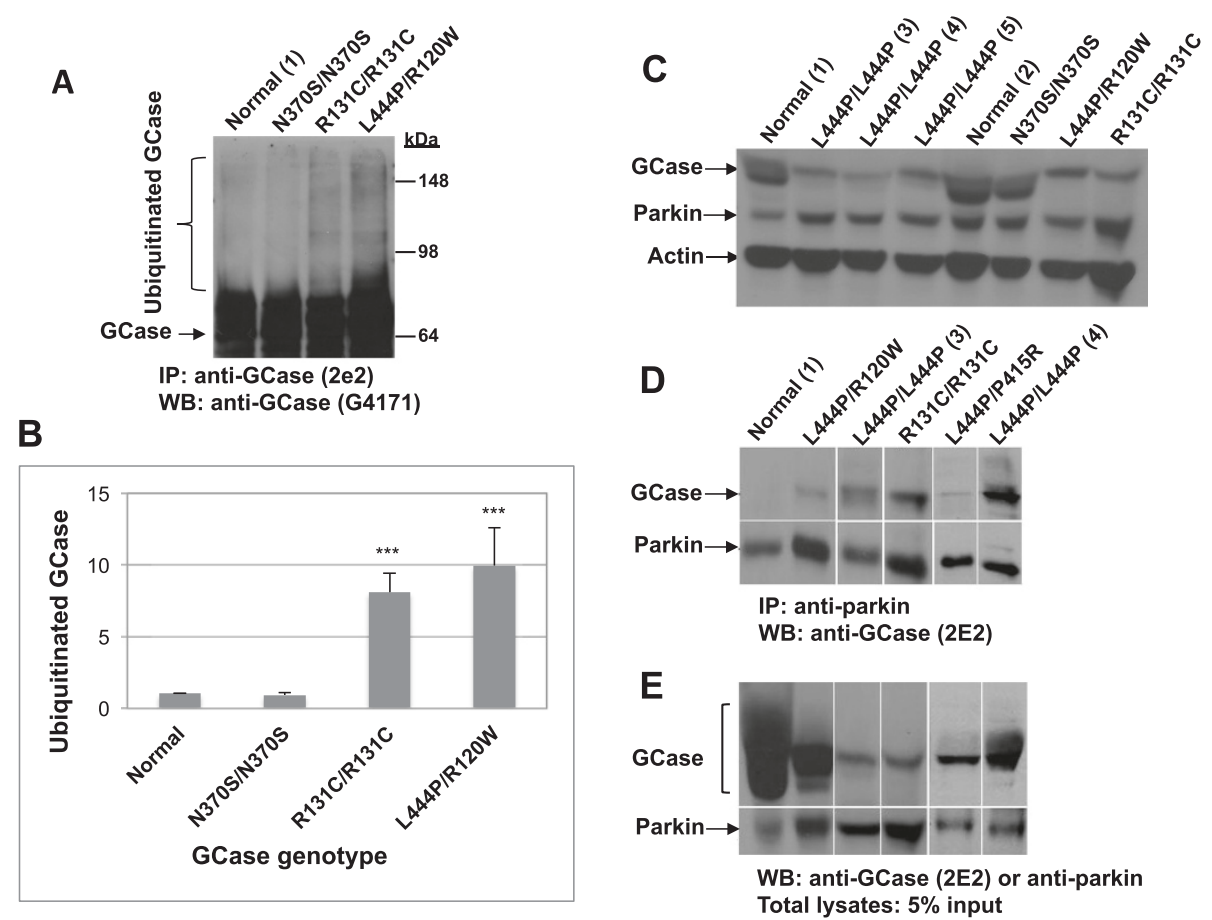

Figure 1 Mutant GCase undergoes ubiquitination and associates with parkin. (A) Protein lysates were prepared from MG-132-treated GD-derived skin fibroblasts or normal skin fibroblasts under denaturing conditions. GCase was immunoprecipitated with monoclonal anti-GCase antibody and subjected to western blot analysis and interaction with polyclonal anti-GCase antibodies. (B) Densitometry was used to quantify the level of ubiquitination. To normalize the results, intensity of ubiquitinated GCase in each lane was divided by the intensity of total GCase in the same lane. The value obtained for normal cells was considered as 1. The results represent the mean \pm SEM of 3-6 independent experiments. ***P $<0.001$ in Student $t$-test. (C) Lysates were prepared from MG-132-treated GD-derived skin fibroblasts or from normal skin fibroblasts. They were subjected to western blot analysis and interaction with anti-GCase antibody, anti-parkin antibody, or anti-actin antibody as a loading control. (D) Parkin-containing complexes were immunoprecipitated from lysates of MG-132-treated GD-derived skin fibroblasts or normal skin fibroblasts with anti-parkin antibody. They were subjected to western blot analysis and interaction with anti-GCase antibody. (E) For loading control, 5\% of lysates were subjected to SDS-PAGE and western blot analysis with anti-GCase or anti-parkin antibodies. Patients' details appear in Table 1. Numbers in parenthesis denote patient-derived cell lines, shown in Table 1.

skin fibroblasts were transfected with shRNA directed against endogenous parkin. As shown in Figure 2C, down-regulation of parkin led to stabilization of mutant GCase in GD-derived fibroblasts originated from patient but not in control fibroblasts, indicating that parkin mediates degradation of mutant GCase.

\section{Competition between PARIS and mutant GCase}

As shown thus far, parkin interacts with mutant GCase and mediates its degradation. We showed in a previous study that parkin, expressed in HEK293 cells, mediates K48 polyubiquitination and proteasomal degradation of mutant, but not normal, transfected GCase [36]. Since PD is characterized by death of dopaminergic neurons in the substantia nigra pars compacta region of the brain, and accumulation of pro-apoptotic parkin substrates have been documented, we wondered whether a competition exists between known pathogenic parkin substrates and mutant GCase.
One of the substrates of parkin is PARIS (PArkin Interactiong Substrate, ZNF746). PARIS undergoes parkin-dependent polyubiquitination and proteasomal degradation. Non-ubiquitinated PARIS shuttles to the nucleus where it serves as a major transcriptional repressor of PGC1 $\alpha$ (peroxisome proliferator-activated receptor gamma [PPAR $\gamma$ ] coactivator- $1 \alpha$ ). The latter is a master regulator of mitochondrial biogenesis through induction of NRF1 (nuclear respiratory factor-1) gene expression [33]. One of the targets of NRF1 is the ATPase $5 \beta$ gene that encodes the beta subunit of complex $\mathrm{V}$ of the oxidative phosphorylation machinery in the mitochondria (see Figure 3A). PARIS was shown to accumulate in the brains of PD patients, with no concomitant PARIS mRNA increase, indicating regulation of PARIS at the protein level [33].

Based on the above, and on our results showing that mutant GCase is a parkin substrate, we chose to test whether transcription of PGC1 $\alpha, \mathrm{NRF} 1$ and ATPase $5 \beta$ is 


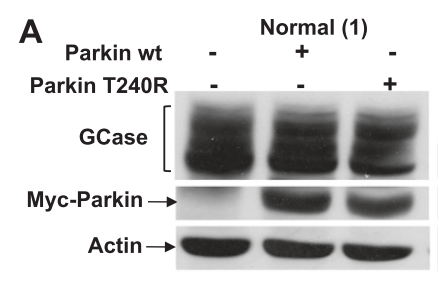

B

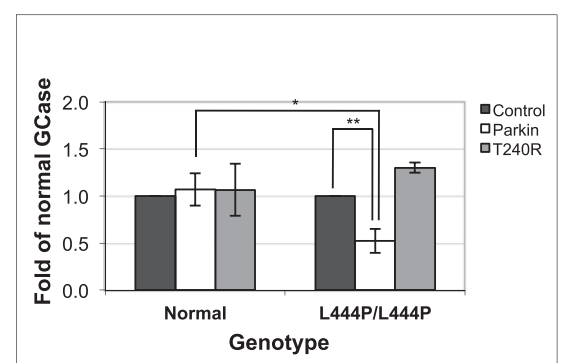

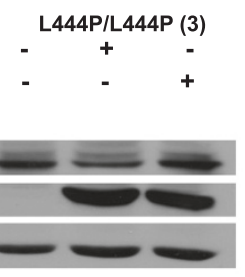

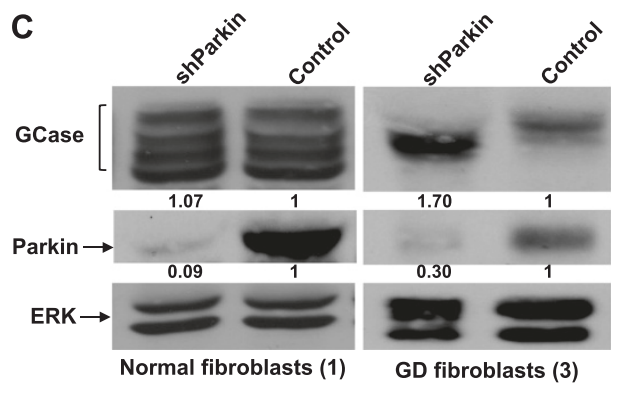

Figure 2 Parkin mediates degradation of mutant GCase. (A) Skin fibroblasts from a GD patient or normal skin fibroblasts were transfected with wt or mutant myc-parkin (T240R). Forty-eight hours later cell lysates were prepared and subjected to western blot analysis. The corresponding blot was interacted with anti-GCase, anti-myc and anti-actin antibodies, as a loading control. (B) To normalize the results, the blots were scanned and GCase intensity at each lane was divided by the intensity of actin. The value obtained for non-transfected cells was considered as 1. The results represent the mean $\pm S E M$, of three independent experiments. ${ }^{*} \mathrm{P}<0.02$, ${ }^{* *} \mathrm{P}<0.01$ in Student $t$-test. (C) Skin fibroblasts from a normal individual or from a GD patient were transfected with shRNA containing plasmid designed to down-regulate parkin expression (shParkin) and pLKO.1 plasmid harbouring shRNA against GFP as a control (control). Forty-eight hours later, cell lysates were prepared and subjected to western blot analysis. The corresponding blot was interacted with anti-parkin, anti-GCase, and anti-ERK antibodies as a loading control. To quantify the results, the blots were scanned and GCase or parkin intensity at each lane was divided by the intensity of ERK1/2 in the same lane. The value obtained for control (in normal or GD cells) was considered as 1. The numbers appear below the blots. The cells used in this experiment derived from patient no. 3 and normal individual no. 1 (see Table 1).

A

B

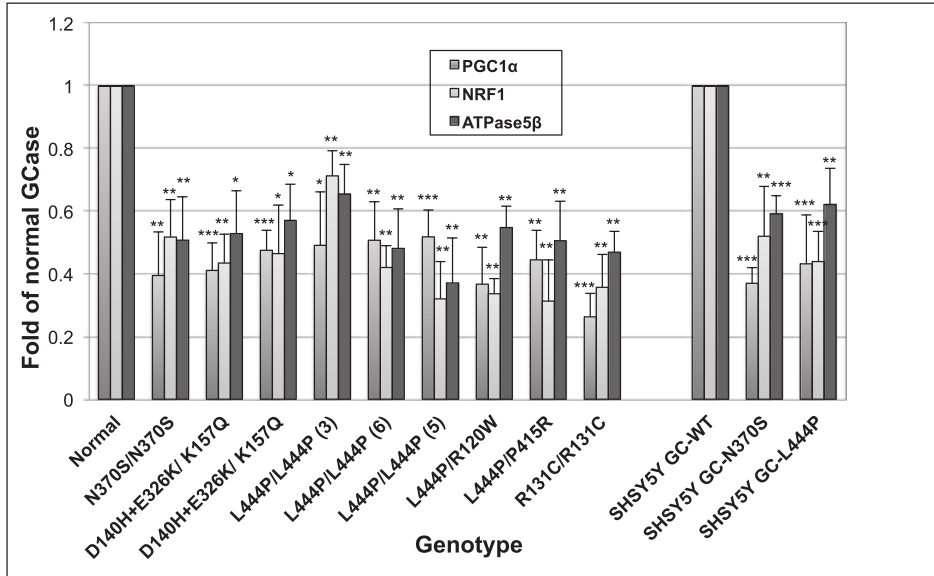

Figure 3 mRNA level of genes modulated by PARIS is down-regulated in GD fibroblasts or SHSY5Y cells expressing mutant GCase. (A) Under normal conditions, PARIS represses the expression of PGC1a, which leads to transcriptional inhibition of NRF1 and as a result also of ATPase $5 \beta$. In GD derived cells, due to competition of PARIS with mutant GCase on parkin availability, a larger fraction of PARIS shuttles to the nucleus. As a result, there is a marked decrease in transcription of PGC1a, NRF1 and ATPase5 $\beta$. (B) mRNA was extracted from normal or GD-derived fibroblasts and from SHSY5Y cells expressing normal or mutant GCase variants. It was subjected to quantitative real-time PCR analysis using primers specific for PGC1a, NRF1 or ATPase5 $\beta$. The mRNA levels of PGC1a, NRF1 and ATPase $5 \beta$ are presented as a fold of decrease compared to that detected for normal fibroblasts. Values represent the mean \pm SEM of 3-7 independent experiments. ${ }^{*} P<0.05$, ${ }^{* *} \mathrm{P}<0.005,{ }^{* * *} \mathrm{P}<0.001$ in Student $t$-test. Numbers in parenthesis denote cell lines detailed in Table 1. Normal represents the average of cell lines 1 and 2 (Table 1). 
repressed in GD-derived fibroblasts. The results, presented in Figure 3B, show a significant decrease in mRNA level of the three tested genes. Our results indicated the same decrease in mRNA level of PGC1 $\alpha$, NRF1 and ATPase $5 \beta$ in human dopaminergic neuroblastoma-derived cells in tissue culture (SHSY5Y), stably expressing mutant GCase [36] in comparison to their level in the same cells expressing normal GCase. These results indicated that the presence of mutant GCase leads to decreased transcription of genes regulated by PARIS, suggesting that a competition exists between PARIS and mutant GCase. To confirm these results, we tested whether increasing amounts of GFPtagged PARIS in SHSY5Y cells, stably expressing normal or mutant GCase, leads to stabilization of mutant but not normal GCase. The results, presented in Figure 4, showed that with elevated amounts of PARIS in the cells, the level of the N370S mutant GCase increased 2-fold and the amount of the L444P mutant GCase variant increased 4fold in comparison to the normal human GCase, expressed under the same competitive conditions.

To summarize, our results imply that mutant GCase and PARIS compete on the availability of parkin. Thus, presence of mutant GCase leads to accumulation of cytoplasmic PARIS and down-regulation of genes associated with mitochondrial biogenesis, which may lead to cell death.

\section{Competition between ARTS and mutant GCase}

Another parkin substrate is the pro-apoptotic protein ARTS (Apoptosis Related protein in TGF $\beta$ Signaling pathway, Sept4_i2) [34]. ARTS is a resident of the mitochondrial outer membrane, but upon apoptotic stimuli it rapidly translocates to the cytoplasm where it binds to and inhibits XIAP (E3 ubiquitin ligase X-linked inhibitor of apoptosis), leading to caspase activation and cell death $[40,41]$. Accumulation of ARTS in cells renders them more susceptible to apoptosis [40,42-44]. We tested a possible competition between ARTS and mutant GCase in dopaminergic cells. SHSY5Y cells, stably expressing normal or the N370S mutant GCase, were transfected with increasing amounts of ARTS-expressing plasmid. The results (Figure 5A and B) strongly indicate that overexpression of ARTS leads to accumulation of the N370S mutant but not of normal GCase.

\section{Mutant GCase enhances cleavage of caspase 3 and caspase 9, leading to apoptosis}

Translocation of ARTS from the mitochondria to the cytosol following apoptotic stimuli leads to cleavage of caspase 3 and caspase 9 [42]. We have shown that mutant GCase competes with ARTS on the availability of parkin. Therefore, upon apoptotic stimuli and in the presence of mutant

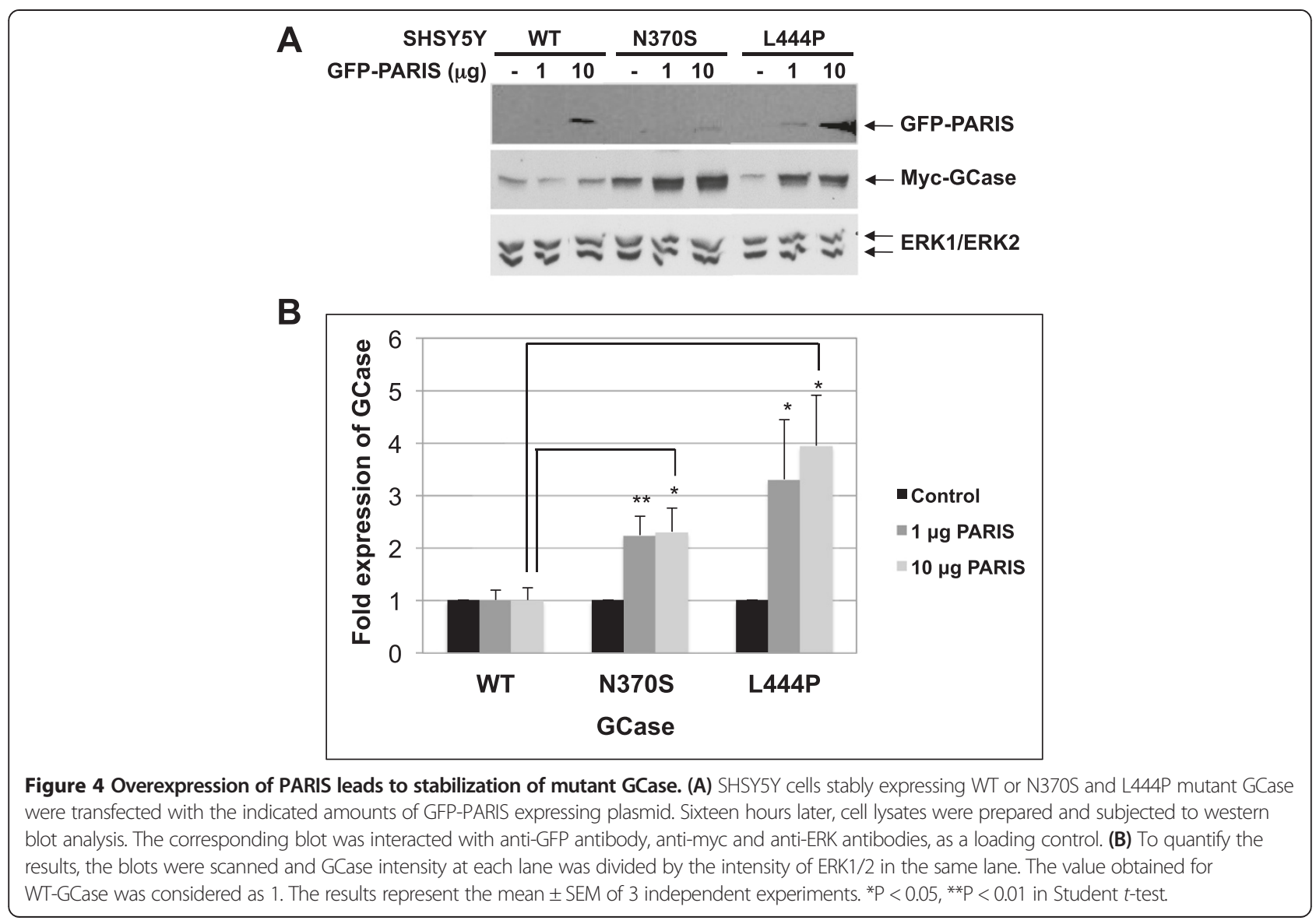




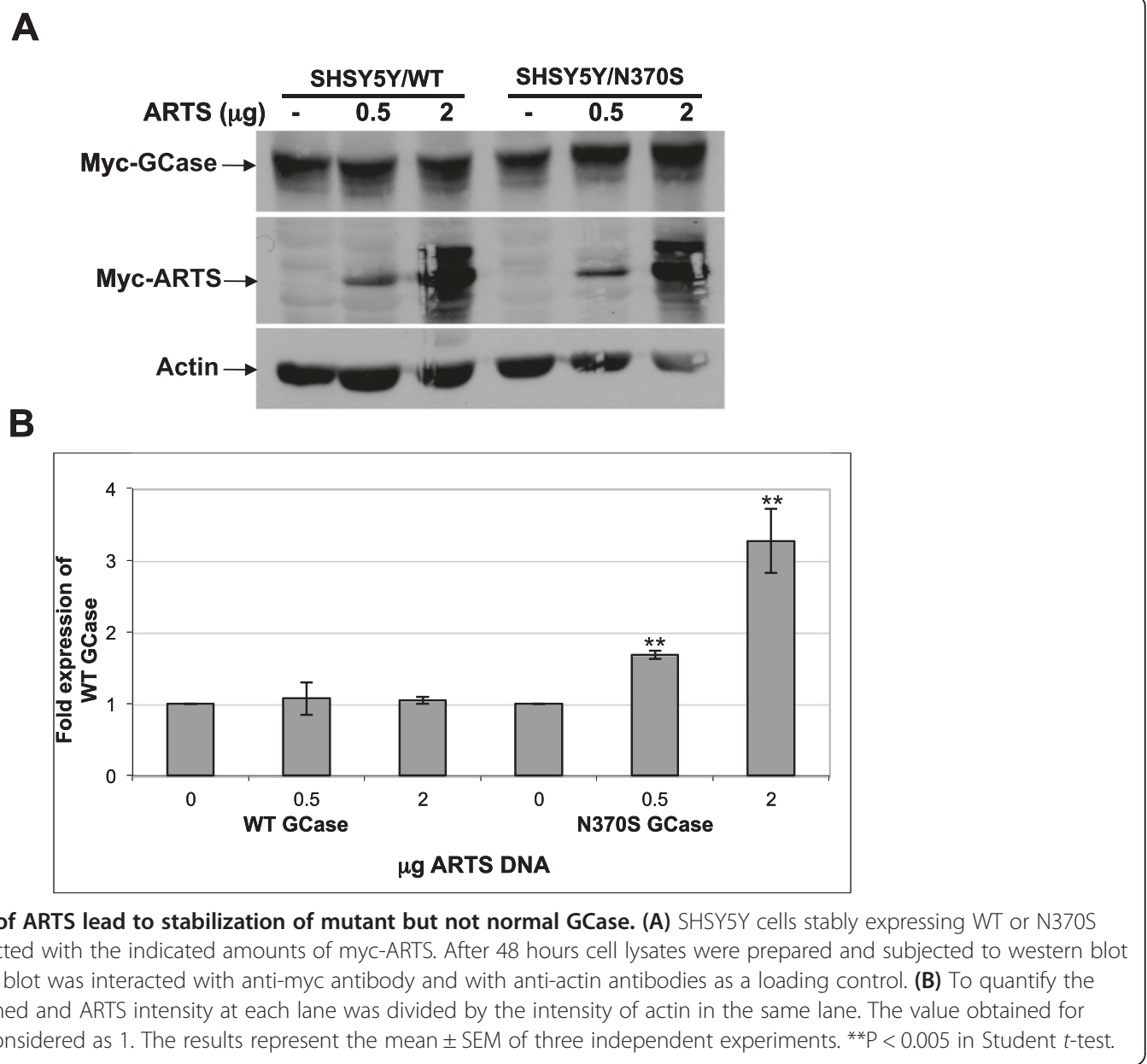

GCase, ARTS should accumulate, inducing cleavage of caspase 3 and 9. To test this assumption, cleavage of caspase 3 and 9 was assayed in staurosporine-stimulated SHSY5Y cells stably expressing normal or N370S mutant GCase. The results, presented in Figure 6A and B, indicate that the apoptotic stimuli was followed by an increase in the amount of cleaved caspase 3 and caspase 9 in SHSY5Y cells expressing N370S mutant GCase in comparison to SHSY5Y cells expressing normal GCase. We also tested whether this staurosporine-induced cleavage of caspase 3 and caspase 9 as well as another stimulus (hydrogen peroxide) lead to apoptosis. As presented in Figure 6C, SHSY5Y cells stably expressing the N370S or the L444P mutant GCase were more susceptible to apoptotic stimulus than SHSY5Y cells stably expressing the normal GCase.

Our results strongly indicate that mutant GCase leads to sensitization of cells to apoptotic stimuli and death, involving caspase cleavage.

\section{Discussion}

In the present study we show that endogenous mutant GCase variants undergo polyubiquitination. They associate with parkin, which mediates their degradation, as shown by overexpression of normal or mutant parkin in GDderived skin fibroblasts or by transfection of parkin shRNA into GD-derived fibroblasts. Mutant GCase variants compete with the pathogenic parkin substrates PARIS and ARTS. Based on the presented results, we hypothesize that the presence of mutant GCase in dopaminergic cells of GD patients or carriers of GD mutations leads to accumulation of pathogenic parkin substrates, which contributes to their death and to the development of PD.

Mutations in parkin, a RING domain-containing E3 ligase, are the most common cause of autosomal recessive PD $[26,45]$. Parkin plays a role in the ERAD of misfolded ER proteins, and it is upregulated by unfolded protein stress [46]. It induces proteasome-mediated mitophagy and degradation of mitofusins [47]. Loss of parkin activity leads to the accumulation of its pathogenic substrates PARIS and AIMP2 (aminoacyl tRNA synthetase complexinteracting multifunctional protein-2) and to $\alpha$-synuclein aggregation, ultimately causing cell death [28]. PARIS is a transcription factor that undergoes parkin-mediated ubiquitination and proteasomal degradation in the cytoplasm. 


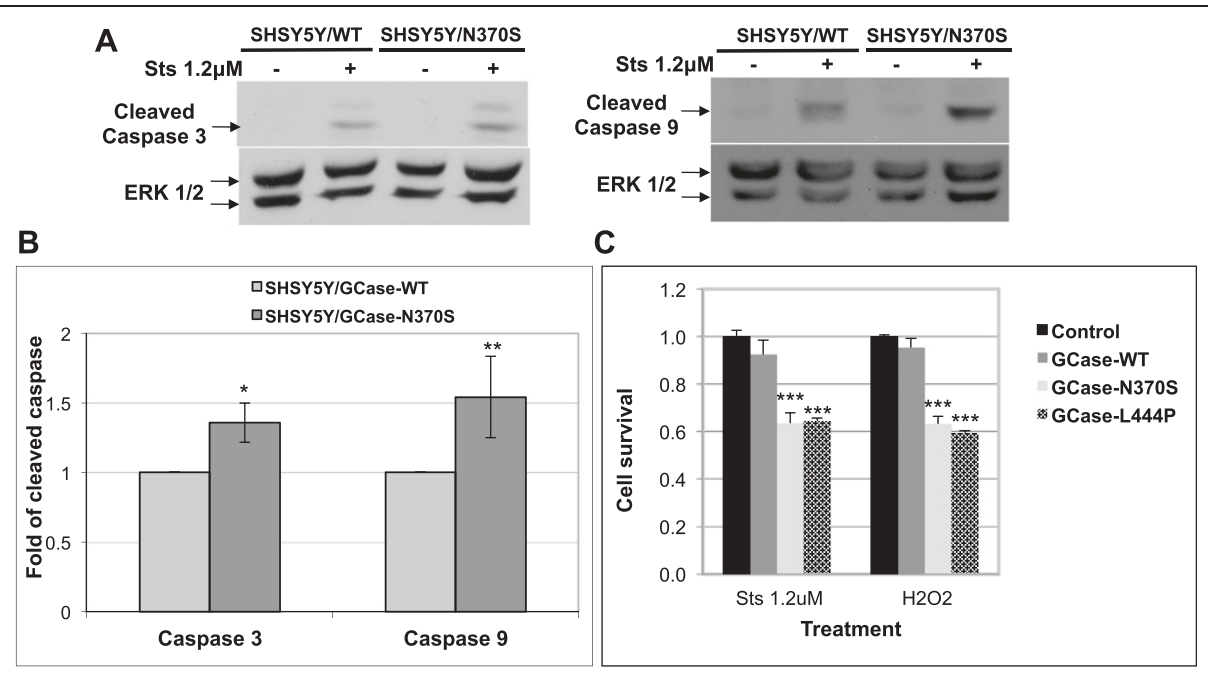

Figure 6 Presence of mutant GCase increases apoptotic stimuli induced cleavage of caspase 3 and caspase 9 leading to cell death.

(A) SHSY5Y cells, stably expressing WT or N370S mutant GCase, were treated with $1.2 \mu \mathrm{M}$ of staurosporine for 3 hours, after which cell lysates were prepared and subjected to western blot analysis. The corresponding blot was interacted with anti-cleaved caspase 3 antibody or anti-cleaved caspase 9 antibody and anti-ERK antibodies, as a loading control. (B) To quantify the results, the blots were scanned and intensity of cleaved caspase 3 or cleaved caspase 9 at each lane was divided by the intensity of ERK $1 / 2$ in the same lane. The value obtained for cells expressing WT GCase was considered as 1. The results represent the mean \pm SEM of five independent experiments. ${ }^{*} \mathrm{P}<0.05,{ }^{*} \mathrm{P}<0.02$ in Student $t$-test. (C) SHSY5Y cells, stably expressing either WT or N370S or L444P mutant GCase variants or naïv SHSY5Y cells (control), were treated with $1.2 \mu \mathrm{M}$ of staurosporine for 3 hours or $1 \%$ hydrogen peroxide $\left(\mathrm{H}_{2} \mathrm{O}_{2}\right)$ for 1 hour after which cells were subjected to XTT colorimetric assay (Biological industries, Beit Haemek, Israel). The results represent the mean \pm SEM of three to five independent experiments. ${ }^{* * *}$ $<0.001$ in Student $t$-test.

Its non-ubiquitinated form shuttles to the nucleus and represses the transcription of NRF1, whose target is ATPase $5 \beta$. The latter encodes the beta subunit of complex $\mathrm{V}$ of the oxidative phosphorylation machinery in the mitochondria [33]. AIMP2 is another substrate of parkin, present in Lewy body inclusions in the substantia nigra of PD patients $[48,49]$.

Parkin promotes clearance of depolarized mitochondria by mitophagy [50-52]. Mitophagy is the selective engulfment of mitochondria by autophagosomes and their subsequent degradation by lysosomes [53,54]. Parkin is recruited to depolarized mitochondria where it mediates the ubiquitination of the mitochondrial outer membrane proteins mitofusin 1 and 2 [51,55], thereby preventing the fusion of damaged mitochondria and targeting them for degradation by mitophagy $[47,51,55,56]$. Interestingly, disease-associated parkin mutants were also shown to be defective in promoting mitophagy [57].

Another parkin substrate is Miro, a component of the primary motor/adaptor complex that anchors kinesin to the mitochondrial surface. Endogenous Miro levels were significantly decreased in HEK293T cells overexpressing parkin, resulting in the release of kinesin from mitochondria and the detachment of mitochondria from microtubules [58].

Based on our results and the literature, we assume that occupation of parkin with mutant GCase affects its availability to bind other substrates, including PARIS,
ARTS, mitofusins and Miro. This leads to decreased mitochondria biogenesis, prevents mitophagy and results in retention of damaged mitochondria, eventually leading to death of dopaminergic cells and to development of PD.

Phosphorylation of parkin by $\mathrm{c}$-Abl and its interaction with 14-3-3eta were shown to inactivate its activity. Thus, the non-tyrosine receptor kinase c-Abl mediates dopaminergic stress or dopaminergic neurotoxin-induced tyrosine 143 phosphorylation of parkin. This modification leads to the inactivation of parkin, the subsequent accumulation of pathogenic parkin substrates, and to the eventual death of dopaminergic cells [59,60]. Interaction of parkin with 14-3-3eta was shown to negatively regulate its activity. Alpha-synuclein abrogated the 14-3-3eta-induced suppression of parkin activity [54]. However, PD-causing mutants of $\alpha$-synuclein failed to activate parkin due to their inability to bind 14-3-3eta $[59,60]$.

Since carriers of GD mutations and Type 1 GD patients are prone to develop PD, and since the common denominator between these two populations is the existence of mutant GCase, we assume that the latter is a dominant predisposing factor for development of PD. It is of note that no GCase substrate (i.e. glucosylceramide) accumulation has ever been documented in brains of carriers of GD mutations or those of Type 1 GD patients. In a recent work we have shown that transgenic expression of mutant GCase in dopaminergic/serotonergic cells of the 
Drosophila melanogaster brain leads to development of PD-like symptoms, exemplified by the death of dopaminergic cells and motor impairment (climbing disability) $[61]$.

Parkin is not the only E3 ubiquitin ligase involved in degradation of mutant GCase variants. Other E3 ubiquitin ligases such as c-Cbl [62] and Itch [61] have been recently reported to mediate the degradation of mutant GCase variants. It is not unusual that multiple E3 ligases contribute to the stability of substrates. Thus, at least five different E3 ligases have been already documented for p53 [63-67]. It is reasonable to assume that, under different conditions and in different cells, various E3 ligases regulate the levels of mutant GCase variants by modulating its polyubiquitination and proteasomal degradation.

\section{Conclusions}

To summarize, in the present work we show that mutant GCase variants undergo parkin-mediated degradation, a process that leads to the accumulation of pathogenic substrates such as PARIS and ARTS in cells. We assume that accumulation of such substrates in the dopaminergic cells of the brain is one of the factors that lead to their death and development of PD.

\section{Competing interests}

The authors declare that they have no competing interests.

\section{Authors' contributions}

$\mathrm{IBB}$ and $\mathrm{DR}$ designed the experiments, performed them and wrote the manuscript; SL supplied a plasmid; MH designed the experiments and participated in the manuscript preparation. All authors read and approved the final manuscript.

\section{Acknowledgements \\ We thank Dr. Mirella Filocamo (Centro di Diagnostica Genetica e Biochimica delle Malattie Metaboliche, IRCCS G. Gaslini, Genova, Italy) and Dr. Roscoe Brady (NIH, Bethesda, MD, USA) for GD derived skin fibroblasts and Dr. Eli Sprecher (Department of Dermatology, Tel Aviv Sourasky Medical Center, Tel Aviv, Israel) for normal fibroblasts. We thank Dr. Ted M. Dawson (Solomon H. Snyder Department of Neuroscience, Johns Hopkins University School of Medicine, Baltimore, MD, USA) for a kind gift of the PARIS expressing plasmid. We would like to express our appreciation to Dr. Doron Calo, Research Authority, Tel Aviv University, for critical reading of the manuscript. This work was supported by a grant from The Israeli Ministry of Health (MH). Inna Bendikov-Bar was the recipient of Gertner and SAIA fellowships, administered by Tel Aviv University.}

\section{Author details}

'Department of Cell Research and Immunology, Life Sciences, Tel Aviv University, Levanon St, Ramat Aviv 69978, Israel. ${ }^{2}$ Department of Human Biology, Natural Sciences, Haifa University, Haifa, Israel.

Received: 17 March 2014 Accepted: 28 May 2014

Published: 16 June 2014

\section{References}

1. Beutler E: Gaucher disease. Adv Genet 1995, 32:17-49.

2. Beutler E: Gaucher disease: multiple lessons from a single gene disorder. Acta Paediatr Suppl 2006, 95:103-109.
3. Ron I, Horowitz M: ER retention and degradation as the molecular basis underlying Gaucher disease heterogeneity. Hum Mol Genet 2005, 14:2387-2398.

4. Maor G, Rencus-Lazar S, Filocamo M, Steller H, Segal D, Horowitz M: Unfolded protein response in Gaucher disease: from human to Drosophila. Orphanet J Rare Dis 2013, 8:140.

5. Aharon-Peretz J, Rosenbaum H, Gershoni-Baruch R: Mutations in the glucocerebrosidase gene and Parkinson's disease in Ashkenazi Jews. N Engl J Med 2004, 351:1972-1977.

6. Bembi B, Zambito Marsala S, Sidransky E, Ciana G, Carrozzi M, Zorzon M, Martini C, Gioulis M, Pittis MG, Capus L: Gaucher's disease with Parkinson's disease: clinical and pathological aspects. Neurology 2003, 61:99-101.

7. Clark LN, Nicolai A, Afridi S, Harris J, Mejia-Santana H, Strug L, Cote L, Louis ED, Andrews H, Waters C, Ford B, Frucht S, Fahn S, Mayeux R, Ottman R, Marder K: Pilot association study of the beta-glucocerebrosidase N370S allele and Parkinson's disease in subjects of Jewish ethnicity. Mov Disord 2005, 20:100-103.

8. Eblan MJ, Walker JM, Sidransky E: The glucocerebrosidase gene and Parkinson's disease in Ashkenazi Jews. N Engl J Med 2005, 352:728-731. author reply 728-731.

9. Goker-Alpan O, Giasson BI, Eblan MJ, Nguyen J, Hurtig HI, Lee VM, Trojanowski JQ, Sidransky E: Glucocerebrosidase mutations are an important risk factor for Lewy body disorders. Neurology 2006, 67:908-910

10. Goker-Alpan O, Schiffmann R, LaMarca ME, Nussbaum RL, Mclnerney-Leo A, Sidransky E: Parkinsonism among Gaucher disease carriers. J Med Genet 2004, 41:937-940.

11. Schlossmacher MG, Cullen V, Muthing J: The glucocerebrosidase gene and Parkinson's disease in Ashkenazi Jews. N Engl J Med 2005, 352:728-731. author reply 728-731.

12. Sidransky E, Nalls MA, Aasly JO, Aharon-Peretz J, Annesi G, Barbosa ER, Bar-Shira A, Berg D, Bras J, Brice A, Chen CM, Clark LN, Condroyer C, De Marco EV, Dürr A, Eblan MJ, Fahn S, Farrer MJ, Fung HC, Gan-Or Z, Gasser T, Gershoni-Baruch R, Giladi N, Griffith A, Gurevich T, Januario C, Kropp P, Lang AE, Lee-Chen GJ, Lesage $S$, et al: Multicenter analysis of glucocerebrosidase mutations in Parkinson's disease. N Engl I Med 2009, 361:1651-1661.

13. Zimran A, Neudorfer O, Elstein D: The glucocerebrosidase gene and Parkinson's disease in Ashkenazi Jews. N Engl J Med 2005, 352:728-731. author reply 728-731.

14. Kalinderi K, Bostantjopoulou S, Paisan-Ruiz C, Katsarou Z, Hardy J, Fidani L: Complete screening for glucocerebrosidase mutations in Parkinson disease patients from Greece. Neurosci Lett 2009, 452:87-89.

15. Lesage S, Anheim M, Condroyer C, Pollak P, Durif F, Dupuits C, Viallet F, Lohmann E, Corvol JC, Honore A, Rivaud S, Vidailhet M, Dürr A, Brice A, for the French Parkinson's Disease Genetics Study Group: Large-scale screening of the Gaucher's disease-related glucocerebrosidase gene in Europeans with Parkinson's disease. Hum Mol Genet 2011, 20:202-210.

16. Seto-Salvia N, Pagonabarraga J, Houlden $\mathrm{H}$, Pascual-Sedano B, Dols-lcardo O, Tucci A, Paisan-Ruiz C, Campolongo A, Anton-Aguirre S, Martin I, Muñoz L, Bufill E, Vilageliu L, Grinberg D, Cozar M, Blesa R, Lleó A, Hardy J, Kulisevsky J, Clarimón J: Glucocerebrosidase mutations confer a greater risk of dementia during Parkinson's disease course. Mov Disord 2012, 27:393-399.

17. Giraldo P, Capablo JL, Alfonso P, Garcia-Rodriguez B, Latre P, Irun P, de Cabezon AS, Pocovi M: Neurological manifestations in patients with Gaucher disease and their relatives, it is just a coincidence? J Inherit Metab Dis 2011 , 34:781-787.

18. Moraitou M, Hadjigeorgiou G, Monopolis I, Dardiotis E, Bozi M, Vassilatis D, Vilageliu L, Grinberg D, Xiromerisiou G, Stefanis L, Michelakakis H: beta-Glucocerebrosidase gene mutations in two cohorts of Greek patients with sporadic Parkinson's disease. Mol Genet Metab 2011, 104:149-152.

19. Neumann J, Bras J, Deas E, O'Sullivan SS, Parkkinen L, Lachmann RH, Li A, Holton J, Guerreiro R, Paudel R, Segarane B, Singleton A, Lees A, Hardy J, Houlden H, Revesz T, Wood NW: Glucocerebrosidase mutations in clinical and pathologically proven Parkinson's disease. Brain 2009, 132:1783-1794.

20. Dauer W, Przedborski S: Parkinson's disease: mechanisms and models. Neuron 2003, 39:889-909.

21. Shulman JM, De Jager PL, Feany MB: Parkinson's disease: genetics and pathogenesis. Annu Rev Pathol 2011, 6:193-222. 
22. Braak H, Del Tredici K, Rub U, de Vos RA, Jansen Steur EN, Braak E: Staging of brain pathology related to sporadic Parkinson's disease. Neurobiol Aging 2003, 24:197-211.

23. Le W, Sayana P, Jankovic J: Animal models of Parkinson's disease: a gateway to therapeutics? Neurotherapeutics 2014, 11:92-110.

24. Simuni T, Sethi K: Nonmotor manifestations of Parkinson's disease. Ann Neurol 2008, 64(Suppl 2):S65-S80.

25. Mazzulli JR, Xu YH, Sun Y, Knight AL, McLean PJ, Caldwell GA, Sidransky E, Grabowski GA, Krainc D: Gaucher disease glucocerebrosidase and alpha-synuclein form a bidirectional pathogenic loop in Synucleinopathies. Cell 2011, 146:37-52.

26. Kitada T, Asakawa $S$, Hattori $N$, Matsumine $H$, Yamamura $Y$, Minoshima S, Yokochi M, Mizuno Y, Shimizu N: Mutations in the parkin gene cause autosomal recessive juvenile parkinsonism. Nature 1998, 392:605-608.

27. Lucking CB, Durr A, Bonifati V, Vaughan J, De Michele G, Gasser T, Harhangi BS, Meco G, Denefle P, Wood NW, Agid Y, Brice A, French Parkinson's Disease Genetics Study Group, European Consortium on Genetic Susceptibility in Parkinson's Disease: Association between early-onset Parkinson's disease and mutations in the parkin gene. N Engl J Med 2000, 342:1560-1567.

28. Dawson TM, Dawson VL: Parkin plays a role in sporadic Parkinson's disease. Neurodegener Dis 2014, 13:69-71.

29. Moore DJ: Parkin: a multifaceted ubiquitin ligase. Biochem Soc Trans 2006, 34:749-753.

30. Geisler S, Holmstrom KM, Treis A, Skujat D, Weber SS, Fiesel FC, Kahle PJ, Springer W: The PINK1/Parkin-mediated mitophagy is compromised by PD-associated mutations. Autophagy 2010, 6:871-878.

31. Olzmann JA, Chin LS: Parkin-mediated K63-linked polyubiquitination: a signal for targeting misfolded proteins to the aggresome-autophagy pathway. Autophagy 2008, 4:85-87.

32. Cookson MR: Parkin's substrates and the pathways leading to neuronal damage. Neuromolecular Med 2003, 3:1-13.

33. Shin JH, Ko HS, Kang H, Lee Y, Lee Yl, Pletinkova O, Troconso JC, Dawson VL, Dawson TM: PARIS (ZNF746) repression of PGC-1alpha contributes to neurodegeneration in Parkinson's disease. Cell 2011, 144:689-702.

34. Kemeny S, Dery D, Loboda Y, Rovner M, Lev T, Zuri D, Finberg JP, Larisch S: Parkin promotes degradation of the mitochondrial pro-apoptotic ARTS protein. PLoS One 2012, 7:e38837

35. Dawson TM, Dawson VL: The role of parkin in familial and sporadic Parkinson's disease. Mov Disord 2010, 25(Suppl 1):S32-S39.

36. Ron I, Rapaport D, Horowitz M: Interaction between parkin and mutant glucocerebrosidase variants: a possible link between Parkinson disease and Gaucher disease. Hum Mol Genet 2010, 19:3771-3781.

37. Hershko A, Eytan E, Ciechanover A, Haas AL: Immunochemical analysis of the turnover of ubiquitin-protein conjugates in intact cells. Relationship to the breakdown of abnormal proteins. J Biol Chem 1982, 257:13964-13970.

38. Bendikov-Bar I, Ron I, Filocamo M, Horowitz M: Characterization of the ERAD process of the L444P mutant glucocerebrosidase variant. Blood Cells Mol Dis 2011, 46:4-10.

39. Tsuji S, Martin BM, Barranger JA, Stubblefield BK, LaMarca ME, Ginns El: Genetic heterogeneity in type 1 Gaucher disease: multiple genotypes in Ashkenazic and non-Ashkenazic individuals. Proc Natl Acad Sci U S A 1988 85:2349-2352.

40. Gottfried Y, Rotem A, Lotan R, Steller H, Larisch S: The mitochondrial ARTS protein promotes apoptosis through targeting XIAP. EMBO J 2004 23:1627-1635.

41. Bornstein B, Edison N, Gottfried Y, Lev T, Shekhtman A, Gonen H, Rajalingam K, Larisch S: X-linked Inhibitor of Apoptosis Protein promotes the degradation of its antagonist, the pro-apoptotic ARTS protein. Int J Biochem Cell Biol 2012, 44:489-495.

42. Edison N, Zuri D, Maniv I, Bornstein B, Lev T, Gottfried Y, Kemeny S, Garcia-Fernandez M, Kagan J, Larisch S: The IAP-antagonist ARTS initiates caspase activation upstream of cytochrome $C$ and SMAC/Diablo. Cell Death Differ 2012, 19:356-368.

43. Larisch S, Yi Y, Lotan R, Kerner H, Eimerl S, Tony Parks W, Gottfried Y, Birkey Reffey S, de Caestecker MP, Danielpour D, Book-Melamed N, Timberg R, Duckett CS, Lechleider RJ, Steller H, Orly J, Kim SJ, Roberts AB: A novel mitochondrial septin-like protein, ARTS, mediates apoptosis dependent on its P-loop motif. Nat Cell Biol 2000, 2:915-921.
44. Lotan R, Rotem A, Gonen H, Finberg JP, Kemeny S, Steller H, Ciechanover A, Larisch S: Regulation of the proapoptotic ARTS protein by ubiquitin-mediated degradation. J Biol Chem 2005, 280:25802-25810.

45. Abbas N, Lucking CB, Ricard S, Durr A, Bonifati V, De Michele G, Bouley S, Vaughan JR, Gasser T, Marconi R, Broussolle E, Brefel-Courbon C, Harhangi BS, Oostra BA, Fabrizio E, Böhme GA, Pradier L, Wood NW, Filla A, Meco G, Denefle $P$, Agid $Y$, Brice A: A wide variety of mutations in the parkin gene are responsible for autosomal recessive parkinsonism in Europe. Hum Mol Genet 1999, 8:567-574.

46. Imai Y, Soda M, Takahashi R: Parkin suppresses unfolded protein stress-induced cell death through its E3 ubiquitin-protein ligase activity. J Biol Chem 2000, 275:35661-35664.

47. Tanaka A, Cleland MM, Xu S, Narendra DP, Suen DF, Karbowski M, Youle RJ: Proteasome and p97 mediate mitophagy and degradation of mitofusins induced by Parkin. J Cell Biol 2010, 191:1367-1380.

48. Corti O, Hampe C, Koutnikova H, Darios F, Jacquier S, Prigent A, Robinson JC, Pradier L, Ruberg M, Mirande M, Hirsch E, Rooney T, Fournier A, Brice A: The $\mathrm{p} 38$ subunit of the aminoacyl-tRNA synthetase complex is a Parkin substrate: linking protein biosynthesis and neurodegeneration. Hum Mol Genet 2003, 12:1427-1437.

49. Ko HS, von Coelln R, Sriram SR, Kim SW, Chung KK, Pletnikova O, Troncoso J, Johnson B, Saffary R, Goh EL, Song H, Park BJ, Kim MJ, Kim S, Dawson VL, Dawson TM: Accumulation of the authentic parkin substrate aminoacyl-tRNA synthetase cofactor, p38/JTV-1, leads to catecholaminergic cell death. J Neurosci 2005, 25:7968-7978.

50. Narendra D, Tanaka A, Suen DF, Youle RJ: Parkin is recruited selectively to impaired mitochondria and promotes their autophagy. $J$ Cell Biol 2008, 183:795-803.

51. Narendra DP, Jin SM, Tanaka A, Suen DF, Gautier CA, Shen J, Cookson MR, Youle RJ: PINK1 is selectively stabilized on impaired mitochondria to activate Parkin. PLOS Biol 2010, 8:e1000298.

52. Narendra DP, Youle RJ: Targeting mitochondrial dysfunction: role for PINK1 and Parkin in mitochondrial quality control. Antioxid Redox Signal 2011, 14:1929-1938

53. Jin SM, Youle RJ: PINK1- and Parkin-mediated mitophagy at a glance. J Cell Sci 2012, 125:795-799.

54. Youle RJ, Narendra DP: Mechanisms of mitophagy. Nat Rev Mol Cell Biol 2011, 12:9-14.

55. Pallanck LJ: Culling sick mitochondria from the herd. J Cell Bio/ 2010, 191:1225-1227.

56. Gegg ME, Cooper JM, Chau KY, Rojo M, Schapira AH, Taanman JW: Mitofusin 1 and mitofusin 2 are ubiquitinated in a PINK1/parkindependent manner upon induction of mitophagy. Hum Mol Genet 2010, 19:4861-4870

57. Lee JY, Nagano Y, Taylor JP, Lim KL, Yao TP: Disease-causing mutations in parkin impair mitochondrial ubiquitination, aggregation, and HDAC6-dependent mitophagy. J Cell Biol 2010, 189:671-679.

58. Wang X, Winter D, Ashrafi G, Schlehe J, Wong YL, Selkoe D, Rice S, Steen J, LaVoie MJ, Schwarz TL: PINK1 and Parkin target Miro for phosphorylation and degradation to arrest mitochondrial motility. Cell 2011, 147:893-906.

59. Ko HS, Lee Y, Shin JH, Karuppagounder SS, Gadad BS, Koleske AJ, Pletnikova O, Troncoso JC, Dawson VL, Dawson TM: Phosphorylation by the c-Abl protein tyrosine kinase inhibits parkin's ubiquitination and protective function. Proc Natl Acad Sci U S A 2010, 107:16691-16696.

60. Sato S, Chiba T, Sakata E, Kato K, Mizuno Y, Hattori N, Tanaka K: 14-3-3eta is a novel regulator of parkin ubiquitin ligase. EMBO J 2006, 25:211-221.

61. Maor G, Filocamo M, Horowitz M: ITCH regulates degradation of mutant glucocerebrosidase: implications to Gaucher disease. Hum Mol Genet 2013, 22:1316-1327.

62. Lu J, Chiang J, lyer RR, Thompson E, Kaneski CR, Xu DS, Yang C, Chen M, Hodes RJ, Lonser RR, Brady RO, Zhuang Z: Decreased glucocerebrosidase activity in Gaucher disease parallels quantitative enzyme loss due to abnormal interaction with TCP1 and c-Cbl. Proc Natl Acad Sci U S A 2010, 107:21665-21670.

63. Dornan D, Wertz I, Shimizu H, Arnott D, Frantz GD, Dowd P, O'Rourke K, Koeppen $H$, Dixit VM: The ubiquitin ligase COP1 is a critical negative regulator of p53. Nature 2004, 429:86-92.

64. Haupt $Y$, Maya R, Kazaz A, Oren M: Mdm2 promotes the rapid degradation of p53. Nature 1997, 387:296-299. 
65. Kubbutat MH, Jones SN, Vousden KH: Regulation of p53 stability by Mdm2. Nature 1997, 387:299-303.

66. Laine A, Ronai Z: Regulation of p53 localization and transcription by the HECT domain E3 ligase WWP1. Oncogene 2007, 26:1477-1483.

67. Leng RP, Lin Y, Ma W, Wu H, Lemmers B, Chung S, Parant JM, Lozano G, Hakem R, Benchimol S: Pirh2, a p53-induced ubiquitin-protein ligase, promotes p53 degradation. Cell 2003, 112:779-791.

doi:10.1186/1750-1172-9-86

Cite this article as: Bendikov-Bar et al:: Parkin-mediated ubiquitination of mutant glucocerebrosidase leads to competition with its substrates PARIS and ARTS. Orphanet Journal of Rare Diseases 2014 9:86.

\section{Submit your next manuscript to BioMed Central and take full advantage of:}

- Convenient online submission

- Thorough peer review

- No space constraints or color figure charges

- Immediate publication on acceptance

- Inclusion in PubMed, CAS, Scopus and Google Scholar

- Research which is freely available for redistribution 